\title{
Ocean primary production calculated by spectral and broad-band models
}

\author{
Margareth Kyewalyanga ${ }^{1,2}$, Trevor Platt ${ }^{3}$, Shubha Sathyendranath ${ }^{1,3}$ \\ ${ }^{1}$ Department of Oceanography, Dalhousie University, Halifax, Nova Scotia, Canada B3H 4J1 \\ ${ }^{2}$ Institute of Marine Sciences, University of Dar-es-Salaam, Box 668, Zanzibar, Tanzania \\ ${ }^{3}$ Biological Oceanography Division, Bedford Institute of Oceanography, Box 1006, Dartmouth, Nova Scotia, Canada B2Y 4 A2
}

\begin{abstract}
Water-column primary production was determined by the ${ }^{14} \mathrm{C}$ in situ method during the spring bloom in the North Atlantic Ocean. For the same samples, the parameters of the photosynthesislight $(P-I)$ curve were determined in broad-band light, and in narrow spectral bands for construction of the action spectrum. Using these parameters, with information on the vertical distribution of chlorophyll, measurements of light absorption by particulate materials, and data on surface irradiance, watercolumn production was calculated using 4 different production models. When compared to in situ primary production measurements, the results show that the spectral model, Model 1, is the best estimator of water-column primary production. Model 2 which used broad-band $\alpha^{B}$ (the initial slope of $P-I$ curve, normalized to biomass $B$ ) with light integrated over wavelength, and Model 4 (broad-band $\alpha^{B}$ and broad-band light), consistently underestimated production by about $25 \%$ and $60 \%$ respectively. However, Model 3 (in which light is computed using a depth-averaged attenuation coefficient, $\bar{K}$, and in which $\alpha^{B}$ is assumed to be wavelength-independent) gave water-column primary production estimates not significantly different from in situ values. It is recommended that the spectral model should be applied, whenever possible, in the computations of water-column primary production. If, however, broad-band $\alpha^{B}$ has to be used in the calculations, it is suggested that light at depth be computed if possible using $\bar{K}$. The use of the fully broad-band model, Model 4, is not recommended. This is because the model gave strongly biased estimates of water-column primary production relative to the observed values.
\end{abstract}

\section{INTRODUCTION}

In many contexts of marine ecosystem analysis, it is required to estimate primary production from knowledge of the phytoplankton biomass and light field. Examples of such applications are in the interpretation of remotely-sensed data on ocean colour (Smith 1981, Smith et al. 1982, Platt \& Herman 1983, Eppley et al. 1985, Platt 1986, Platt \& Sathyendranath 1988 , Platt et al. 1988, Sathyendranath \& Platt 1989b), in the interpretation of field data (Côté \& Platt 1984, Harrison et al. 1985, Herman \& Platt 1986, Lewis et al. 1988, Kiefer et al. 1989, Sathyendranath \& Platt 1989a, Siegel et al. 1990), and in the development of multidisciplinary, numerical models for climate research (Wroblewski et al. 1988, Platt \& Sathyendranath 1991).

The forcing variable for primary production is available light. In computing primary production as a func- tion of light, a basic question to be resolved at the outset is whether to make a wavelength-dependent calculation or a wavelength-averaged one. It is well known that the absorption of light by phytoplankton depends strongly on wavelength (Prieur \& Sathyendranath 1981, Kiefer \& SooHoo 1982, Kishino et al. 1985, Sathyendranath et al. 1987, Sathyendranath \& Platt 1988, Morrow et al. 1989, Bricaud \& Stramski 1990) and that the spectral dependence of rate of photosynthesis at low light is also pronounced (see Lewis et al. 1985a, b, 1986). Likewise, depending on the concentration and type of dissolved and particulate materials present in the water column, the spectral composition of submarine irradiance fields varies with depth (Morel 1978, Atlas \& Bannister 1980, Kirk 1983, Kishino et al. 1984, Bidigare et al. 1987, Sathyendranath \& Platt 1988). A strong case can be developed, therefore, for spectrally-resolved calculations. 
But the spectral dependence of the photosynthesis parameters, or the spectral distribution of the irradiance itself, may not be known in a particular application. Moreover, spectral calculations are considerably more complex than broad-band ones, even if the necessary information is indeed available. The increased complexity becomes a significant problem when the calculations must be carried out repeatedly, such as on many grid points for a numerical model or on many pixels for reduction of a remotely-sensed image. It is not surprising, therefore, that most workers decide in favour of spectrally-averaged calculations.

However, it is desirable to know the magnitude of the error that is incurred through neglect of the wavelength dependence, and to show that it is indeed negligible, before the assumption of spectral independence can be justified. For example, calculations by Sathyendranath et al. (1989), using constant photosynthesis parameters, showed that a broad-band model can overestimate integrated water-column production by as much as $60 \%$ at high chlorophyll concentrations, compared to a spectral model.

In this paper, we compute primary production using both spectral and broad-band approaches for 7 stations in the oligotrophic North Atlantic Ocean, and compare the results with measurements of in situ production. In the spectral approach, both the light transmission underwater and the photosynthetic response of phytoplankton to light are calculated using spectral models. In the broad-band approach, both these functions are considered to be wavelength-independent. The results of the comparison will be useful in any context where it is required to estimate ocean primary production from knowledge of phytoplankton biomass.

\section{PRODUCTION AND LIGHT MODELS}

Four primary production models of varying complexity were compared in this study for their ability to estimate in situ primary production. The observed ${ }^{14} \mathrm{C}$ in situ primary production measurements at 9 depths (in the interval from 1 to $60 \mathrm{~m}$ ) were used as the standard of reference for comparison with the calculated values. The comparisons were limited to the top $60 \mathrm{~m}$, because the euphotic depth (1\% light level) ranged from 55 to $60 \mathrm{~m}$ during the entire sampling period, and within this range (55 to $60 \mathrm{~m}$ ) primary pro-

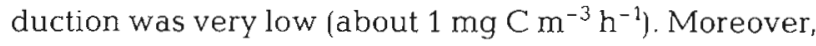
the results of in situ measurements of primary production, made at $75 \mathrm{~m}$ and $100 \mathrm{~m}$ (below the euphotic zone), showed rates not significantly different from zero, confirming that the base of the productive zone must have been between 60 and $75 \mathrm{~m}$.

\section{Model 1: The spectral model}

Because it was the most complete, the spectral model was taken as the benchmark for the 4 production models tested. This model considers all factors treated in this study that affect photosynthetic rate: spectral and angular distribution of submarine light field and spectral dependence of $\alpha^{B}$, the initial slope of photosynthesis-irradiance curves. The computations were performed using 2 alternative production equations.

Model 1a: The equation of Smith (1936): Primary production $P\left(\mathrm{mg} \mathrm{C} \mathrm{m}^{-3} \mathrm{~h}^{-1}\right)$ at depth $z$ was calculated using the equation of Smith (1936) as modified by Sathyendranath \& Platt (1989a) to include the spectral dependence of photosynthesis on the available light:

$$
P(z)=B(z) \Pi(z) / \sqrt{1+\left(\Pi(z) / P_{\mathrm{m}}^{B}(z)\right)^{2}},
$$

(assuming that diffuse light is uniformly distributed and that $\alpha^{B}(\lambda)$ and $P_{\mathrm{m}}^{B}$ do not vary with depth) where

$$
\begin{aligned}
\Pi(z) & =\sec \theta \int_{\lambda_{1}}^{\lambda_{2}} \alpha^{B}(\lambda) I_{\mathrm{d}}(z, \lambda, \theta) \mathrm{d} \lambda \\
& +1.20 \int_{\lambda_{1}}^{\lambda_{2}} \alpha^{B}(\lambda) I_{\mathrm{s}}(z, \lambda) \mathrm{d} \lambda .
\end{aligned}
$$

Here $I_{\mathrm{d}}$ and $I_{\mathrm{s}}$ are the direct and diffuse components of the available light at depth $z$ determined as described below; $\lambda$ is the wavelength from $\lambda_{1}=400 \mathrm{~nm}$ to $\lambda_{2}=$ $700 \mathrm{~nm}_{i} \theta$ is the sun zenith angle in water and 1.20 is the inverse of $\bar{\mu}(=0.83)$, the mean cosine for perfectly diffuse skylight after refraction at a flat sea surface; $B(z)$ is the biomass or chlorophyll a concentration ( $\mathrm{mg} \mathrm{chl} \mathrm{a} \mathrm{m}^{-3}$ ). In Eq. (1), $B$ is used to indicate the active photosynthetic pigments, measured as chlorophyll $a$. The photosynthesis-irradiance $(P-I)$ curve, as defined by Eq. (1), has 2 parameters: the initial slope, $\alpha^{B}(\lambda)\left[\mathrm{mg} \mathrm{C}(\mathrm{mg} \operatorname{chl} \alpha)^{-1} \mathrm{~h}^{-1}\left(\mathrm{E} \mathrm{m}^{-2} \mathrm{~h}^{-1} \mathrm{~nm}^{-1}\right)^{-1}\right]$, and the assimilation number, $P_{\mathrm{m}}^{B}\left[\mathrm{mg} \mathrm{C}(\mathrm{mg} \text { chl a })^{-1} \mathrm{~h}^{-1}\right]$. Note that $\alpha^{B}(\lambda)$ and $P_{\mathrm{m}}^{B}$ are normalized to chl a concentration. The assimilation number is taken to be wavelength-independent (Pickett \& Myers 1966). The spectrum that represents the wavelength-dependence of $\alpha^{B}$ is known as the action spectrum. The wavelength interval used was $5 \mathrm{~nm}$, and the wavelength range of interest corresponds to the photosynthetically active radiation (PAR)

The production values $P(z)$, calculated using Eq. (1), were integrated through time and depth to give the daily, integrated water-column primary production for comparison with the depth-integrated value of the in situ measurements.

The light input for this production model was computed using the spectral model of Sathyendranath \& Platt (1988), which takes into consideration the spectral and angular distribution of the underwater light 
field. The total downwelling spectral irradiance, $I(z, \lambda)$ $\left(E \mathrm{~m}^{-2} \mathrm{~h}^{-1} \mathrm{~nm}^{-1}\right)$, is expressed as the sum of direct and diffuse components:

$$
I(z, \lambda)=I_{\mathrm{d}}(z, \lambda)+I_{\mathrm{s}}(z, \lambda) .
$$

These components were computed as:

and

$$
\begin{aligned}
& I_{\mathrm{d}}(z, \lambda)=I_{\mathrm{d}}(z-\Delta z, \lambda) \mathrm{e}^{-K_{\mathrm{d}}(\lambda) \Delta z} \\
& I_{\mathrm{s}}(z, \lambda)=I_{\mathrm{s}}(z-\Delta z, \lambda) \mathrm{e}^{-K_{\mathrm{s}}(\lambda) \Delta z} .
\end{aligned}
$$

Here, $K_{\mathrm{d}}$ and $K_{\mathrm{s}}$ are the vertical attenuation coefficients for the direct and diffuse components, respectively. They were given by:

and

$$
K_{\mathrm{d}}(\lambda)=\left[a(\lambda)+b_{\mathrm{b}}(\lambda)\right] / \cos \theta
$$

$$
K_{\mathrm{s}}(\lambda)=\left[a(\lambda)+b_{\mathrm{b}}(\lambda)\right] / \bar{\mu}_{1}
$$

where $a\left(\mathrm{~m}^{-1}\right)$ is the sum of $a_{w 1}$ the absorption coefficient of pure sea water, and $a_{p}$, the absorption coefficient of particulate materials.

Since the absorption coefficient of particulate materials depends on their concentration, $a_{p}(\lambda)$ was calculated as the product of pigment concentration, $C\left(\mathrm{mg} \mathrm{m}^{-3}\right)$, and the specific absorption coefficient of particles, $a_{p} \cdot(\lambda)\left(\mathrm{m}^{2} \mathrm{mg}^{-1}\right)$ :

$$
a_{p}(\lambda)=C a_{p}^{*}(\lambda)
$$

where the asterisk indicates normalization to pigment concentration. Note that $C$ is different from $B$, used earlier. Here, $C$ accounts for total pigments, which means photosynthetically-active pigments as well as phaeopigments (the degradation products). The backscattering coefficient $b_{b}(\lambda)\left(\mathrm{m}^{-1}\right)$ was given as:

$$
b_{b}(\lambda)=b_{w}(\lambda) \times 0.5+b_{p}(\lambda) \times 0.005
$$

where $b_{w}(\lambda)$ and $b_{p}(\lambda)$ are scattering coefficients of sea water and particulate materials respectively at wavelength $\lambda$. The constants 0.5 and 0.005 are the ratios of backscattering to total scattering for sea water and particles respectively, as explained in Sathyendranath \& Platt (1988). The coefficient $b_{\mathrm{p}}$ depends on pigment concentration; its value at $550 \mathrm{~nm}$ was computed using the equation of Morel (1980):

$$
b_{\mathrm{p}}(550)=0.12 C^{0.63}
$$

The particle attenuation coefficient at $550 \mathrm{~nm}$, $c_{\mathrm{p}}(550)$, was then given by:

$$
c_{\mathrm{p}}(550)=a_{\mathrm{p}}(550)+b_{\mathrm{p}}(550)
$$

Assuming that the total attenuation coefficient due to particulate materials, $c_{\mathrm{p}}$, is wavelength independent
(Sathyendranath \& Platt 1988$), c_{p}(550)$ becomes a representative value for any wavelength $\lambda$. The spectral values of $b_{\mathrm{p}}$ were then derived from Eq. (11) as follows:

$$
b_{p}(\lambda)=c_{p}(550)-a_{p}(\lambda)
$$

Note that the coefficient $a_{p}$ and the pigment concentration $C$ were determined by direct measurements, and the other coefficients were computed as in Sathyendranath \& Platt (1988).

The initial estimate of sea-surface irradiance was made using the clear-sky model of Bird (1984). The model accounts for aerosol transmittance, watervapour absorption, Rayleigh scattering and ozone absorption. However, since the model of Bird assumes clear-sky conditions, it was necessary to correct the initial estimate for the presence of clouds. The computed spectral values of $I_{\mathrm{s}}$ and $I_{\mathrm{d}}$ at the surface were therefore scaled, such that the wavelength integral at the surface matched the measured PAR value. In other words, the spectral forms, $I_{\mathrm{d}}(\lambda)$ and $I_{\mathrm{s}}(\lambda)$, at the surface were derived from clear-sky model calculations, but the magnitude of PAR was measured directly.

Model 1b: The equation of Platt et al. (1980): Eq. (1) does not admit photoinhibition. However, in situ production measured at one of the stations showed signs of photoinhibition at the surface, and therefore, primary production was also calculated using an alternative expression that could account for photoinhibition. Thus, primary production for that station (April 12) was computed using the equation of Platt et al. (1980), modified to include the dependence of $\alpha^{B}$ and $I$ on wavelength:

$P(z)=B(z) P_{\mathrm{s}}^{B}\left(1-\exp (-\Pi(z)) / P_{\mathrm{s}}^{B}\right) \exp \left(-\beta^{B} \Pi(z) / P_{\mathrm{s}}^{B}\right)$,

where $\Pi(z)$ is as defined in Eq. (2), $P_{s}^{B}$ is the maximum photosynthetic potential rate (normalized to biomass) the sample would attain in the absence of photoinhibition, and the parameter $\beta^{B}$ (same units as $\alpha^{B}$ ) characterizes photoinhibition. It was assumed, in the absence of any knowledge on the spectral dependence of $\beta^{B}$. that this parameter is wavelength independent.

For the remaining stations, where photoinhibition was not a problem $\left(\beta^{B}=0\right)$, production was computed using the reduced form of Eq. (13) (Platt \& Sathyendranath 1991):

$$
\left.P(z)=B(z) P_{\mathrm{m}}^{B}\left(1-\exp (-\Pi(z)) / P_{\mathrm{m}}^{B}\right)\right)
$$

\section{Model 2: Broad-band $\alpha^{B}$ and spectral $I$}

Model 2, which uses a broad-band $\alpha^{B}$ and spectral light field, is intermediate in the sense that the superior light transmission model was retained, but the wavelength- 
dependence of $\alpha^{B}$ was sacrificed. Use of this model allows us to test the extent to which production estimates are affected by neglecting the spectral dependence of $\alpha^{B}$, while retaining full spectral information in the calculations of underwater light transmission.

In this model, light at depth was calculated as in Model 1, i.e. using the spectral-light model. The light was then integrated through wavelength to obtain $I(z)$, the total PAR at depth $(z)$. Production at depth $z$ was then computed using the equation of Smith (1936) (cf. Eqs. 1 \& 2):

$$
P(z)=B(z) \alpha^{B} I(z) /\left[1+\left(\alpha^{B} I(z) / P_{\mathrm{m}}^{B}\right)^{2}\right]^{1 / 2} .
$$

Integration of $P(z)$ over time and depth gave daily water-column production.

\section{Model 3: Broad-band $\alpha^{B}$, with $I$ calculated from average $K(\bar{K})$}

Model 3, in which the $\alpha^{B}$ values used were those from the broad-band $P-I$ curves, but for which the light computations were based on the depth-averaged vertical attenuation coefficient $\bar{K}$, was intended to be a modified version of Model 2. The idea was to provide an alternative solution to the elaborate computation of $K$ at each depth. The purpose of Model 3 calculations, therefore, was to investigate the feasibility of accurately estimating in situ primary production using the broad-band $\alpha^{B}$ (as in Model 2) and a single depth-averaged attenuation coefficient $(\bar{K})$ for light computation, rather than applying a separate value of $K$ for each depth.

The coefficient $\bar{K}$ was calculated as the slope of the regression of $\ln [I(z) / I(0)]$ on depth (Fig. 1), where $I(z)$ was calculated as in Model 2 and $I(0)$ was the measured PAR just below the sea surface. The coefficients were determined for every hour of the day, to account for the effect of changing angular distribution of the light field with solar elevation. The $\bar{K}$ values obtained were symmetrical about noon. The results for April 12 serve to illustrate the extent of variation in $\bar{K}$ throughout the day: the $\bar{K}$ value at $07: 00 \mathrm{~h}$ differed by $11 \%$ from the noon $\bar{K}$. It is a common practice in field studies to measure $K$ values only once a day, usually at noon. The results show that this practice would lead to an error of, at most, about $10 \%$ in $\bar{K}$ at our sampling station. The $\bar{K}$ in this model simulates the values of $I(z)$ that would be obtained using a PAR light metre.

The coefficient $\bar{K}$ was used to compute light $I(z)$ at a given depth $z$ as follows:

$$
I(z)=I(0) \mathrm{e}^{-\bar{K} z}
$$

Hourly values of primary production at depth $z$ were then computed using Eq. 15. As in previous models, in-
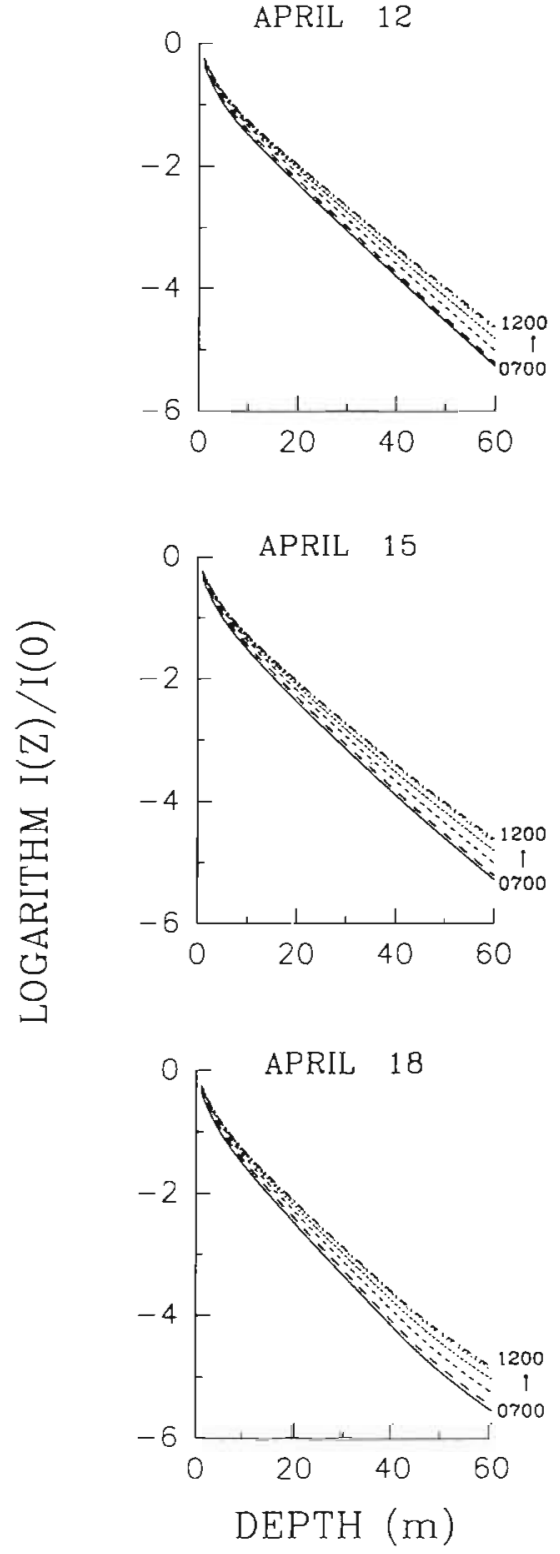

Fig. 1. Sample plots showing light variation with depth for every hour from 07:00 to $17: 00 \mathrm{~h}$ at the sampling station. As light is symmetrical about noon, the curves for 13:00 to 17:00 h overlap those of 07:00 to 11:00. I(z) is light at depth $z$ and $I(0)$ is the measured surface PAR. The slope of each line is equal to average $K, \bar{K}$

tegration over time and depth was carried out to give the daily water-column primary production.

\section{Model 4: The broad-band model}

The broad-band model was the simplest of all the 4 production models. It is the antithesis of Model 1 in that it assumes that all parameters of the light model 
and the production model are independent of wavelength. The model provides a means of estimating the error in computed ocean primary production when the spectral dependence of all the wavelength-dependent parameters is neglected. This model resembles Models $2 \& 3$ in the sense that they all use the broad-band equation of Smith (1936) which ignores the wavelength dependence of $\alpha^{B}$ and $I(z)$. The 3 models differ in the way in which $I(z)$ is computed. In Model 4, the computations of light neglected the wavelengthdependence of light transmission (Model 3 light transmission might also appear to neglect the wavelengthdependence, but note that $\bar{K}$ was obtained as the slope of spectrally-integrated $I(z)$ plotted as a function of depth). The wavelength dependence was eliminated in Model 4 by averaging over wavelength all the spectral parameters used in the light model: specific absorption by total particulate matter, absorption by pure sea water, backscattering coefficient for pure sea water, and specific backscattering coefficient for particulate materials. In other words, a single value for a given depth (unweighted spectral average) was used. The attenuation coefficient was calculated as:

$$
K=\frac{a+b_{b}}{\cos \theta}
$$

where

$$
a=a_{w}+a_{p}
$$

Here, $a_{w}$ takes the spectrally-averaged value of $0.1634\left(\mathrm{~m}^{-1}\right)$. However, $a_{p}$, the absorption coefficient associated with particulate materials, varies with biomass concentration. Therefore $a_{p}$ was obtained from Eq. (8), after spectral averaging of $a_{p}(\lambda)$.

The backscattering coefficient was given as:

$$
b_{\mathrm{b}}=b_{\mathrm{p}} \times 0.005+b_{\mathrm{w}} \times 0.5
$$

The scattering coefficient of sea water, $b_{w}$, was assigned an average value of $0.0023\left(\mathrm{~m}^{-1}\right)$, and the scattering due to particles, $b_{\mathrm{p}}$, which depends on biomass concentration, was based on the scattering coefficient at $550 \mathrm{~nm}$, as in Eq. (10). As in Model 1, $b_{\mathrm{p}}$ was computed using Eqs. (10), (11) \& (12), but the computations (spectral values) were averaged over wavelength. Although $K$ is averaged over wavelength, it is still depth-dependent and time (angular)dependent since the calculations were done for every hour at each depth.

\section{MATERIALS AND METHODS}

Sampling. Measurements were made at a station in the Sargasso Sea, at $37^{\circ} 30^{\prime} \mathrm{N}, 40^{\circ} 00^{\prime} \mathrm{W}$ from 12 to
21 April 1990, during the Canadian JGOFS 1990 cruise of CSS 'Hudson'. Water samples were collected using a submersible pump. All the samples were taken in the morning (at approximately 09:00 h local time) at 9 depths $(1$ to $60 \mathrm{~m})$. Chl a was determined fluorometrically after extraction for $24 \mathrm{~h}$, in the dark, in ice-cold $85 \%$ acetone, by the method of Yentsch \& Menzel (1963) as modified by Holm-Hansen et al. (1965).

Phytoplankton absorption measurements. Absorption measurements were necessary in the computation of light transmission in water since the absorption coefficient, a $\left(\mathrm{m}^{-1}\right)$, was used as input in light models for computation of vertical attenuation coefficient.

Seawater (volumes from 0.5 to 0.751 , depending on chlorophyll concentration) was filtered onto a $25 \mathrm{~mm}$ glass-fibre filter (Whatman GF/F) at low pressure (<5 mm Hg). Optical densities (absorbance values) of total particulate materials at wavelength $\lambda, D_{p}(\lambda)$, with the subscript $p$ indicating particle absorbance, were measured directly using a Beckman DU-64 spectrophotometer in the spectral range 380 to $750 \mathrm{~nm}$, by the method of Shibata (1958) as modified by Kiefer \& SooHoo (1982). Optical density is the ratio $\left(\log _{10}\right)$ of incident irradiance to transmitted irradiance (Kirk 1983).

The $D_{\mathrm{p}}(\lambda)$ values were converted to absorption coefficients (Kishino et al. 1985) as follows:

$$
a_{p}(\lambda)=2.3 D_{p}(\lambda) /(L X)
$$

where $a_{p}(\lambda)$ is the total absorption coefficient of particulate materials at wavelength $\lambda$ and $L$ is the pathlength in metres given by $V / S$, where $V$ is the volume of seawater sample filtered and $S$ is the filtering area of the filter paper. The factor 2.3 is for conversion of $\log _{10}$ to natural logarithm, and $X$ is the pathlength amplification factor (Kiefer \& SooHoo 1982, Mitchell \& Kiefer 1984, 1988a).

To estimate $X$, experiments were performed in the laboratory using cultures of phytoplankton. In these experiments, the absorption coefficient of phytoplankton in suspension was measured and compared with the absorption coefficient of the same cultures measured on filters to obtain the value of $X$ for different wavelengths and optical densities.

Primary production measurements. The narrowband ${ }^{14} \mathrm{C}$ incubations were performed on board the ship in temperature-controlled incubators using the method of Lewis et al. (1985a, b, 1986). The photosynthesis-irradiance relationship was determined for every waveband by linear regression of photosynthesis (normalized to chl a) on irradiance to yield the wavelength-specific initial slope values, $\alpha^{B}(\lambda)[\mathrm{mg} C(\mathrm{mg}$ chl a) $\left.)^{-1} \mathrm{~h}^{-1}\left(\mathrm{E} \mathrm{m}^{-2} \mathrm{~s}^{-1}\right)^{-1}\right)$, of the $P-I$ curve (Fig. 2) that were used to construct an unenhanced action spectrum (see Fig. 4). 


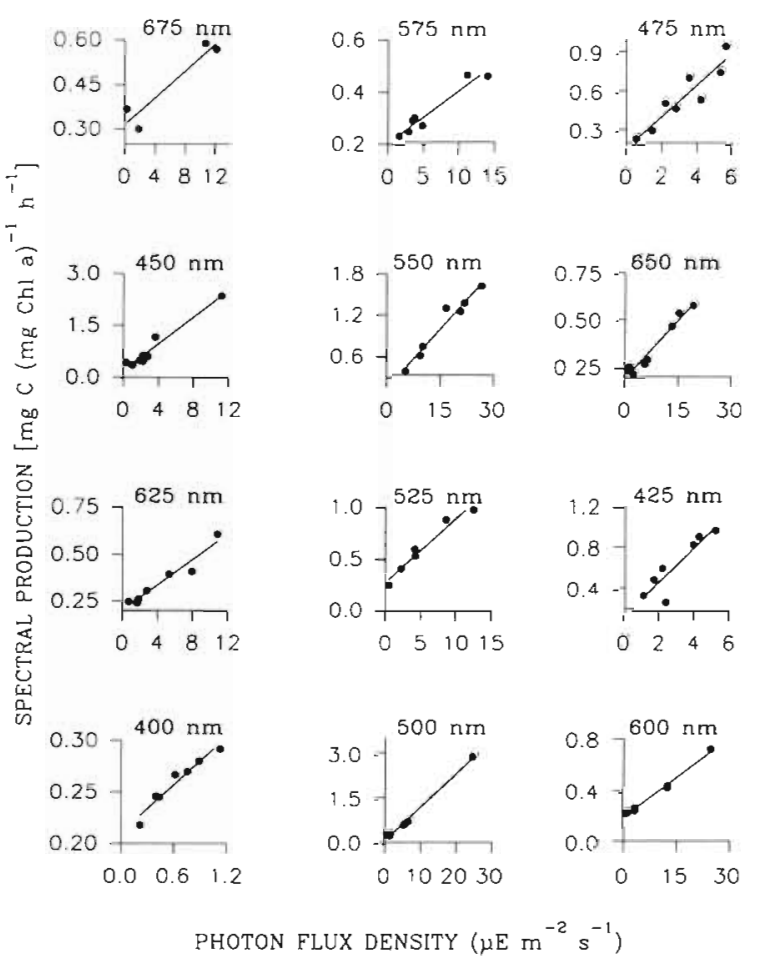

Fig. 2. Sample plots of spectrally-resolved production as a function of irradiance. Each plot represents a $25 \mathrm{~nm}$ waveband. The slope of each line gives the biomass-specific photosynthesis parameter $\alpha^{B}(\lambda)\left[\mathrm{mg} \mathrm{C}(\mathrm{mg} \mathrm{chl} \alpha)^{-1} \mathrm{~h}^{-1}\left(\mu E \mathrm{~m}^{-2} \mathrm{~s}^{-1}\right)^{-1}\right.$, at wavelength $\lambda$

In broad-band $P-I$ experiments, samples were incubated for $3 \mathrm{~h}$ on the ship according to the $\left({ }^{14} \mathrm{C}\right)$ procedure described in Irwin et al. (1990). Photosynthesis parameters $\alpha^{B}, P_{\mathrm{m}}^{B}$ and $\beta^{B}$, all normalized to biomass, were obtained by fitting production values to the equation of Platt et al. (1980).

In situ primary production was measured by the ${ }^{14} \mathrm{C}$ technique (Strickland \& Parsons 1965). Precautions were taken to avoid random errors due to sampling, contamination and post incubation handling (Irwin et al. 1990). Water samples were collected from nine depths using $12 \mathrm{l}$ Niskin bottles at around 05:00 h local time for every sampling day. The samples were placed in $125 \mathrm{ml}$ polycarbonate bottles to which $40 \mu \mathrm{Ci}$ of $\mathrm{NaH}^{14} \mathrm{CO}_{3}$ was added, and incubated at depths from which they were taken. A total of 3 light bottles were deployed at dawn and recovered at dusk (about $12 \mathrm{~h}$ ); the 2 corresponding dark bottles were kept in a darkened cooler at in situ temperatures. After incubation, the samples were filtered on Whatman GF/F filters, and processed as explained in Irwin et al. (1990). The dark bottle values were subtracted from the light bottle values, and photosynthetic rates were calculated as described in Strickland \& Parsons (1972). Integration was carried out over the 9 depths to give daily in situ water-column primary production. Water-column primary production was, thus, given by (Platt $\&$ Irwin 1968):

$$
\int P(z) \mathrm{d} z=\sum_{i=1}^{9} P_{i}(z) D_{i}
$$

where $i$ represents the layer and $D_{i}$ is the thickness of the layer.

\section{RESULTS AND DISCUSSION}

\section{Specific absorption coefficient}

The absorption coefficients of particulate materials, corrected for pathlength amplification, were normalized to the value of the coefficient at $440 \mathrm{~nm}, a_{\mathrm{p}}(440)$, to examine the variation in shape of the absorption spectrum. There was no significant variation in shape of the normalized spectra with depth (Fig. 3a), and the standard deviations of the coefficients, shown in Fig. 3b, were very low in the wavelength interval from 440 to $700 \mathrm{~nm}$. Therefore, the mean normalized spectrum, $a_{p}^{\prime}(\lambda)$ (Fig. 3b), was taken to be representative of all depths and all days. In other words, the shape of the absorption coefficient for particulate materials was held invariant in the spectral light models.

The absolute values of absorption coefficients were obtained by multiplying $a_{p}^{\prime}(\lambda)$ values by the calculated absorption coefficient at $440 \mathrm{~nm}, a_{\mathrm{p}}(440)$, which was obtained using the following equation:

$$
a_{\mathrm{p}}(440)=0.043 \times C^{0.43},
$$

where $C\left(\mathrm{mg} \mathrm{m}^{-3}\right)$ is the sum of concentrations of chlorophyll $a$ and phaeopigments. To obtain Eq. (22), measured particulate absorption coefficients at $440 \mathrm{~nm}$
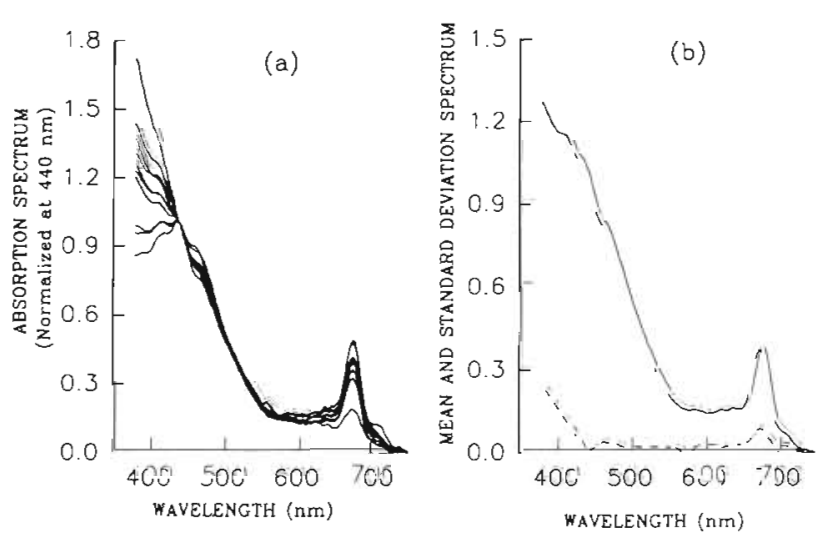

Fig. 3. (a) Total particulate absorption coefficient spectra, based on samples from various depths, in the range from 1 to $60 \mathrm{~m}$. (b) Mean normalized absorption spectrum (-) and standard deviation (---) of the spectra shown in (a). Note the low magnitude of the standard deviation 
were plotted as a function of pigment concentration $C$. The data used were collected in the Sargasso Sea in April 1989 (Goes \& Hoepffner unpubl.) and in April 1990 (this study). The constants in Eq. (22) were obtained by linear regression on log-transformed data $\left(r^{2}=0.55, n=30\right)$.

\section{Phytoplankton action spectra}

As in the case of particulate absorption spectra, the biomass-specific action coefficients, $\alpha^{B}(\lambda)$, were normalized to the value at $440 \mathrm{~nm}$ to study the variability in shape of the action spectrum. Again, in the absence of any systematic variation in shape with depth, and given the low standard deviation (Fig. 4), the mean normalized spectrum $\alpha^{\prime}(\lambda)$ (Fig. 4) was used to define the shape of $\alpha^{B}(\lambda)$ in Model 1 . The absolute values of $\alpha^{B}(\lambda)$ used in the spectral computations were obtained by scaling the $\alpha^{\prime}(\lambda)$ values such that the spectral average (for white light) had the same magnitude as that of the broad-band $\alpha^{B}$. In other words, the scaling factor was given by the ratio of broad-band $\alpha^{B}$ to the spectral average of $\alpha^{\prime}(\lambda)$.

\section{Primary production}

For the 3 rate measurements of carbon fixation - in situ production, action spectrum and the broad-band $P-I$ parameters - we used the same ${ }^{14} \mathrm{C}$ method. The inherent problems associated with the ${ }^{14} \mathrm{C}$ method itself (Richardson 1991) fall outside the scope of this paper.

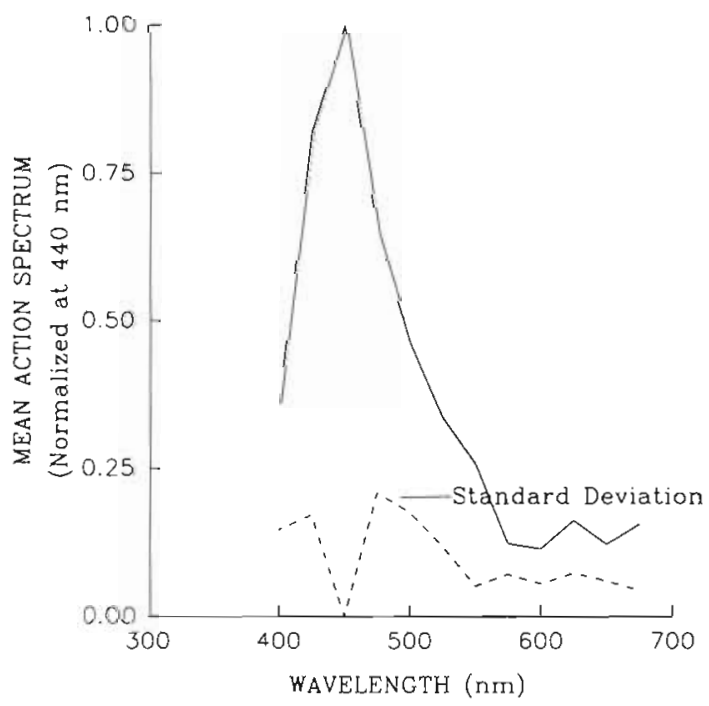

Fig. 4. Mean phytoplankton action spectrum (-). It represents the average of 15 action spectra (not shown) constructed using $\alpha^{B}(\lambda)$ values. Plotted also is the corresponding standard deviation spectrum (-- - -) of the 15 spectra
Daily in situ primary production integrated through depth and time varied by a factor of about 4 during the entire sampling period (Fig, 5). The plot of in situ production as a function of time showed a maximum on April 18 and a minimum on April 21. All 4 primary production models tested could reproduce the shape of the time variation in the in situ production, but with varying success as to the absolute magnitudes (Fig. 5). In the following sections, the results from the different models are discussed in detail.

Production calculated using Model 1. The $P(z)$ values calculated according to the 2 spectrally-resolved models were compared to the corresponding in situ $P(z)$ measurements (Figs. 6 \& 7) for each sampling day and for all days combined. Fig. 6 shows the relationship between Model $1 \mathrm{a}$ and in situ production, while Fig. 7 is an analogous plot for Model 1b. Except for the first sampling day $(\mathrm{p}>0.05, \mathrm{n}=9$ ), the regression slopes of Model 1a production on in situ production, for each day and combined data, were highly significant $(\mathrm{p}<0.001 ; \mathrm{n}=9$ for individual days, $n=63$ for pooled data). The reason for the poor performance of Model 1a on the first sampling day was its inability to account for photoinhibition, a difficulty removed by the use of Model $1 \mathrm{~b}$. The regression slopes of Model $1 \mathrm{~b}$ were highly significant in all cases ( $p<0.001 ; n=9$ for each day, $n=63$ for pooled data).

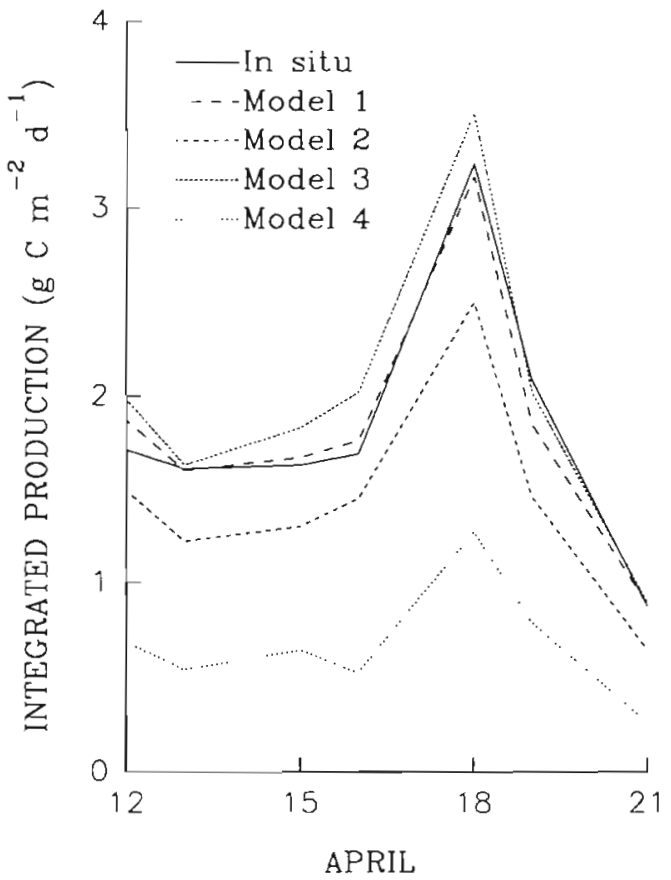

Fig. 5. Comparison of in situ daily water-column primary production with integrated water-column primary production calculated by the 4 models. Notice the similarity in shape. The amplitude of production curves for Models 1 and 3 are not significantly different in magnitude from the in situ curve, whereas those for Models 2 and 4 are significantly lower 


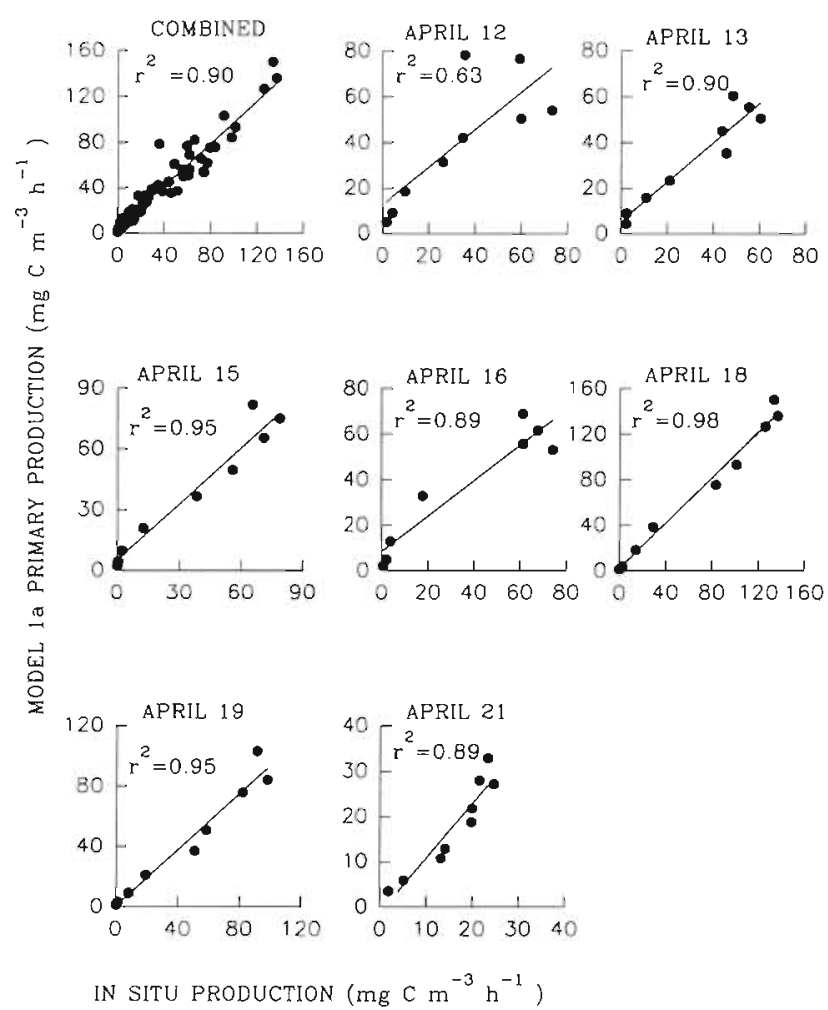

Fig. 6. Comparison of in situ primary production measured at depth $z, P(z)$, with $P(z)$ calculated by Model 1a, for each sampling day and for combined data. The corresponding coefficients of determination $\left(r^{2}\right)$ values are given. In general, the data points lying farther from the origin (high production values) represent $P(z)$ from shallow depths (1 to $15 \mathrm{~m})$, and those closer to the origin represent $P(Z)$ from deeper waters (20 to $60 \mathrm{~m}$ )

The coefficient of determination $r^{2}$ was calculated for each regression: it showed that on any day, at least $89 \%$ of the variance in the in situ production could be explained by Model 1a. In the case of Model $1 \mathrm{~b}$, for pooled data, $95 \%$ of the variance could be explained (Fig. 7).

Integrated primary production results for Model 1 compared well with the in situ integrated production (see Fig. 5, Table 1). That is to say primary production results from Model 1 calculations, both at discrete depths and integrated values, confirm the excellent performance of the spectral model in estimating in situ primary production.

Production calculated using Model 2. Comparisons of the $P(z)$ values calculated using Model 2 with the in situ $P(z)$ measurements, for each sampling day and for all days combined, are shown in Fig. 8. The regression slopes were significant for all days $(p<0.01)$ considered one at a time $(\mathrm{n}=9)$, and highly significant $(p<0.001)$ for the combined data $(n=63)$. The coefficient of determination for pooled data showed that
$85 \%$ of the variance in the in situ production could be explained by Model 2 results (Fig. 8). In other words, $P(z)$ values from Model 2 showed a significant relationship with in situ measurements, even though broad-band $\alpha^{B}$ values were used in computing the production.

The integrated production calculated by Model 2 (Table 1) was significantly lower than the corresponding in situ value on all 7 sampling days, in spite of the excellent correlations between computed and measured $P(z)$ referred to above. The negative bias in production values from Model 2 is explained by the pattern in the model-estimated production at particular depths. This model (1) overestimated production at $1 \mathrm{~m}$ on all sampling days; (2) usually overestimated production at $5 \mathrm{~m}$; and (3) underestimated production at all depths below $5 \mathrm{~m}$ (i.e. from 10 to $60 \mathrm{~m}$ ). Consequently, on all days, when $P(z)$ was integrated over depth (and time) the resultant value was lower than in situ depth-integrated primary production.

These results may be explained as follows. Consider the shape of the action spectrum (Fig. 4): it peaks in the blue region of the spectrum and has a broad minimum in the green. An unweighted spectral average of $\alpha^{B}(\lambda)$ will therefore be smaller than $\alpha^{B}(\lambda)$ in the blue wavelengths and larger than the values of $\alpha^{B}(\lambda)$ in the green

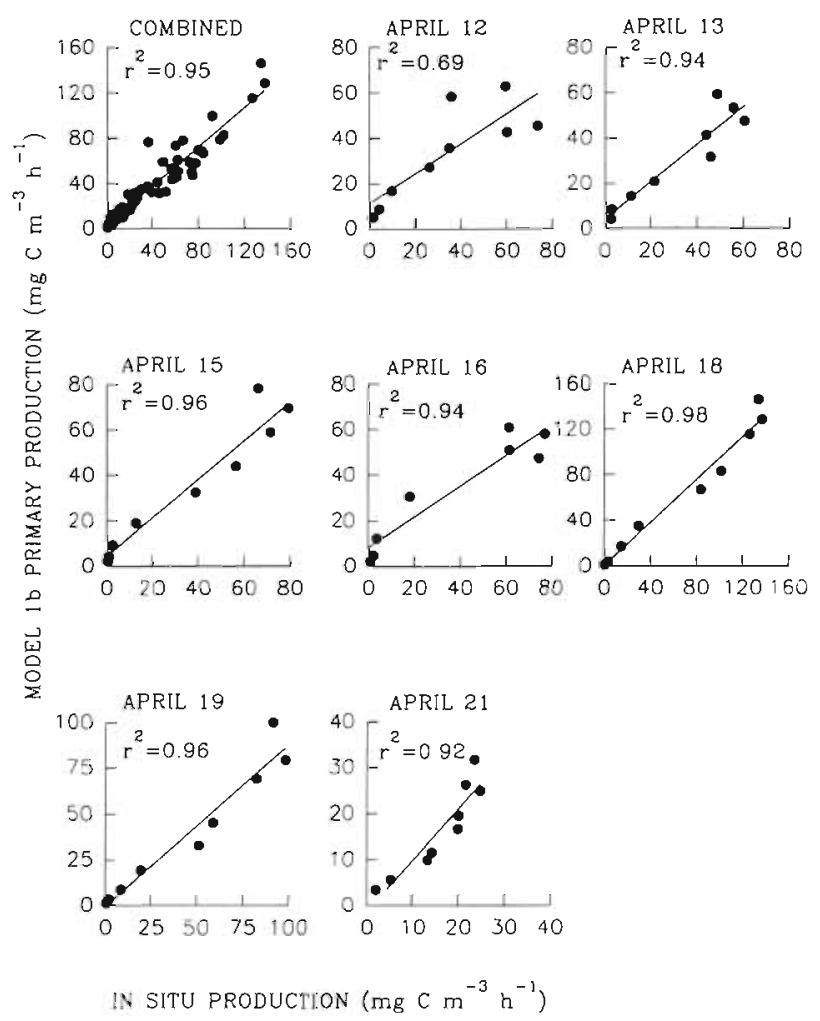

Fig. 7. As for Fig. 6, but comparison of in situ primary production measurements at depths with $P(z)$ calculated by Model $1 \mathrm{~b}$ 


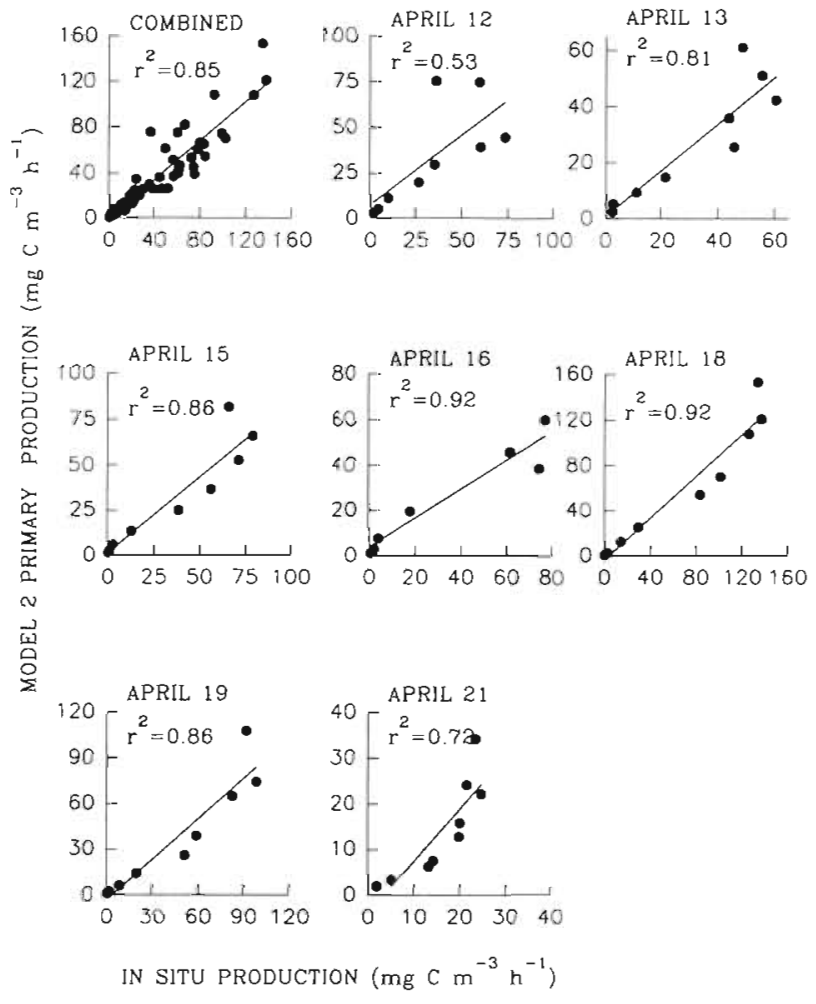

Fig. 8. As for Fig. 6, but comparison of in situ primary production measured at a depth $z, P(z)$, with $P(z)$ calculated by Model 2

(the broad-band $\alpha^{B}$ used in this study is not strictly an unweighted average, it is weighted by the broad-band illumination in the incubator. Nevertheless, it remains true that $\alpha^{B}$ will be less than $\alpha^{B}(\lambda)$ in the blue but greater than $\alpha^{B}(\lambda)$ in the green part of the spectrum).

If primary production is calculated using the broadband $\alpha^{B}$ (or unweighted average of $\alpha^{B}(\lambda)$ ) with $I(z, \lambda)$ integrated over wavelength (interval from 400 to $700 \mathrm{~nm}$, as in Model 2), the resulting value may either underestimate, be the same as, or overestimate the corresponding water-column primary production value, depending on chlorophyll concentration:

(1) In waters with low chlorophyll concentration (in the range 0.01 to $1 \mathrm{mg} \mathrm{m}^{-3}$ ) the underwater light field is generally dominated by blue light. In such cases, the broad-band $\alpha^{B}$ will underestimate the locally dominant component of $\alpha^{B}(\lambda)$ and production computed using $\alpha^{B}$ will be negatively biased. Water-column production will also be underestimated because, at depths where the submarine light is predominantly blue, the product $\alpha^{B}(z) \int I(z, \lambda) \mathrm{d} \lambda$ (Model 2) will be less than the product $\int \alpha^{B}(z, \lambda) I(z, \lambda) \mathrm{d} \lambda$ (Model 1 ) for the reasons given above.

(2) In chlorophyll-rich waters (concentration greater than $2 \mathrm{mg} \mathrm{m}^{-3}$ ), blue light is rapidly attenuated due to absorption by phytoplankton pigments and their degradation products. As a result green light predomi- nates (Sathyendranath \& Platt 1988, Sathyendranath et al. 1989). Therefore, since the broad-band $\alpha^{B}$ is higher than $\alpha^{B}(\lambda)$ in the green part of the spectrum, primary production will be overestimated in this case.

(3) If it happens that underwater light is confined to those wavelengths at which the broad-band $\alpha^{B}$ coincides with the magnitude of $\alpha^{B}(\lambda)$, then the calculated production will be (fortuitously) an accurate estimate of water-column primary production.

Note that the spectral composition of the light at the surface $(0 \mathrm{~m})$ will be the same (slightly higher in the green and the red part of the spectrum; see Fig. 9) for both chlorophyll-poor and chlorophyll-rich oceanic waters. In both cases, surface primary production calculated by Model 2 will overestimate the measured value because broad-band $\alpha^{B}$ will be higher than the spectrally-weighted mean.

Of the 3 cases described above, our sampling station falls in case (1) i.e. optically-clear, chlorophyll-poor waters. The chlorophyll concentration at the station varied from 0.12 to $1.49 \mathrm{mg} \mathrm{m}^{-3}$ for the entire sampling period. Below about $5 \mathrm{~m}$, therefore, the underwater light was predominantly blue. Fig. 9 shows clearly that both underwater light spectrum and the action spectrum have their maximum in the blue region, although they peak at separate wavelengths. Note that both the light spectra and the mean action spectrum are normalized to their respective values at $440 \mathrm{~nm}$. The mean value of the normalized $\alpha^{B}(\lambda)$ spectrum $(0.34)$ is much lower than the value of normalized $\alpha^{B}$ at $475 \mathrm{~nm}(0.58)$. However, as expected, the mean of $\alpha^{B}(\lambda)$

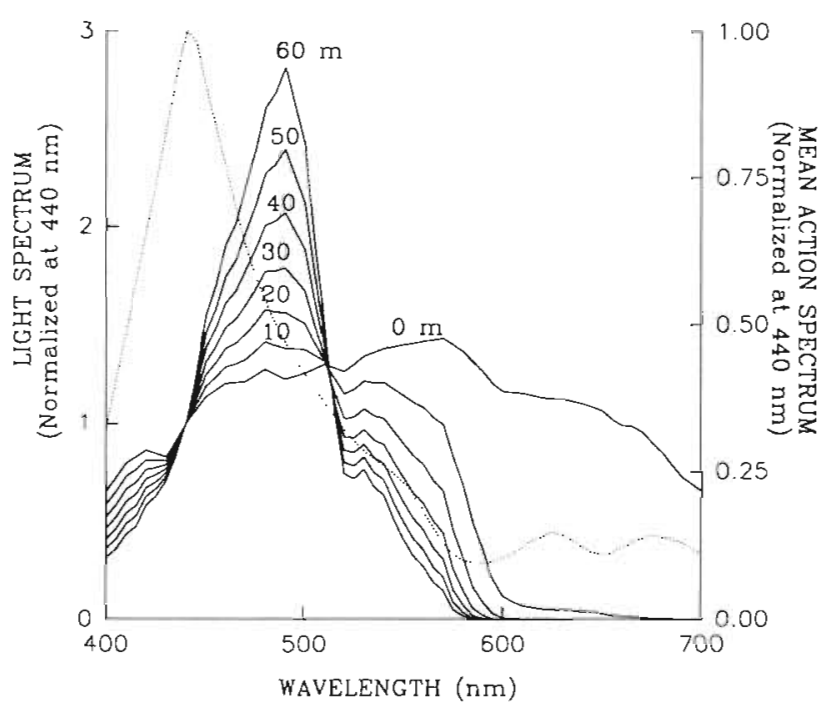

Fig. 9. Sample plot showing $I(z, \lambda)$ spectra for April 12 (continuous lines), at depths from 0 to $60 \mathrm{~m}$, as a function of wavelength. The spectra peak in the blue region. The shape of the light spectra (dominated by blue light) is typical for chlorophyll-poor waters. Plotted together is the mean action spectrum, $\alpha^{B}(\lambda)(\cdots \cdots$.$) which also peaks in the blue region$ 
is higher than the $\alpha^{B}(\lambda)$ values for wavelengths greater than $520 \mathrm{~nm}$ in the green region (normalized $\alpha^{B}(520)=$ 0.32 ). The overall result is a negatively biased value of water-column primary production calculated by Model 2.

Harrison et al. (1985) used similar arguments to explain the difference between production results from simulated in situ incubations using a natural light source and production calculated using photosynthesis parameters measured in incubators equipped with tungsten-halogen lamps.

Production calculated using Model 3. Fig. 10 shows regression plots of $P(z)$, calculated by Model 3, on in situ $P(z)$ for individual days and for the combined data. The slopes of the regression lines were highly significant in all cases $[p<0.01$ for the first day, $p<0.001$ for the remaining 6 days $(n=9)$ and for pooled data $(n=$ 63)], even though Model 3 used broad-band $\alpha^{B}$. The $r^{2}$ values showed that an average of $92 \%$ (for pooled data; Fig. 10) of the variance of the in situ data could be explained by regression of Model 3 results.

Integrated production results calculated by Model 3 were close to the integrated in situ value for all 7 sampling days. Relative to Model 2, Model 3 was a better estimator of in situ integrated production. This is

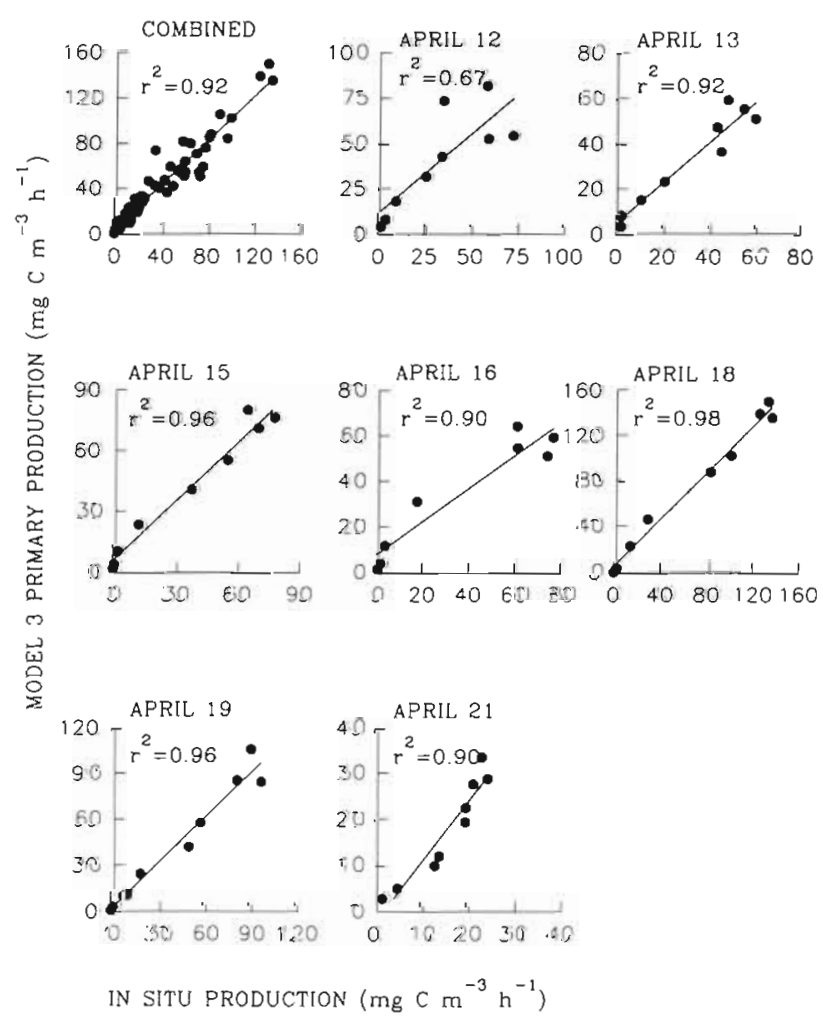

Fig. 10. As for Fig. 6, but comparison of in situ primary production measured at depths, $P(z)$, with primary production calculated by Model 3 at corresponding depths because the calculations of $I(z)$ in Model 3, using $\bar{K}_{\text {, }}$ gave higher light values at all depths compared to $I(z)$ values in Model 2, which were calculated using the spectral light model. This had the effect of increasing primary production calculated by Model 3 at particular depths, compared with that calculated by Model 2 . Thus the negative bias for the integrated production calculated by Model 2 was compensated by the procedure used in Model 3, and the depth-integrated primary production values for Model 3 were in general not significantly different from their in situ counterparts (see Table 1).

An illustration of the use of $\bar{K}$ in computations of water-column production is given in Platt \& Sathyendranath (1991). They computed average diffuse attenuation coefficients for different mixed layers of thickness $Z_{\mathrm{m}},\left\langle K\left(Z_{\mathrm{m}}, B\right)\right\rangle\left(\mathrm{m}^{-1}\right)$, and plotted them as a function of biomass $B\left(\mathrm{mg} \mathrm{m}^{-3}\right)$ (the biomass was assumed to be uniform within a given $Z_{\mathrm{m}}$ ). Their calculated attenuation coefficient for $Z_{\mathrm{m}}=60 \mathrm{~m}$ with biomass of ca $1 \mathrm{mg} \mathrm{m}^{-3}$ matched the $\bar{K}$ values calculated in Model 3 (depthaveraged, from surface to $60 \mathrm{~m}$, but time dependent; see Fig. 1). Moreover, $\zeta$ (the ratio of full spectral solution to the nonspectral solution with $\left.\left\langle K\left(Z_{\mathrm{m}}, B\right)\right\rangle\right\}$, the factor by which the nonspectral estimate of daily mixed-layer production should be multiplied to approximate the full spectral estimate, showed that water-column primary production calculated by the nonspectral model using $\left\langle K\left(Z_{\mathrm{m}}, B\right)\right\rangle$ usually overestimated $(\zeta \leq 1)$ the 'true' value of primary production (that is, production calculated using the spectral model). Similarly, water-column primary production calculated by Model 3 in the present study slightly overestimated in situ production (Fig. 5). To compare the results from this study (Model 3) with those of Platt \& Sathyendranath (1991), the ratio ( $\xi$ ) of in situ water-column production to Model 3 integrated production was determined. The values of $\zeta$ obtained, which varied from 0.84 to 1.03 , were commensurate with those estimated by Platt \& Sathyendranath (1991) for mixed layer depth $=60 \mathrm{~m}$ and chlorophyll concentration of $\leq 1 \mathrm{mg} \mathrm{m}^{-3}$ [recall that production was determined, for this study, up to the base of the euphotic zone $(60 \mathrm{~m})]$.

Notice that, although the value of $\zeta$ was estimated in Platt \& Sathyendranath (1991) for 2 different locations and seasons, winter solstice at mid latitude (December 21 at $50^{\circ} \mathrm{N}$ ) and vernal equinox at the equator (March 21), the calculated values of $\zeta$ from this study carried out during spring at $37^{\circ} 30^{\prime} \mathrm{N}$ had similar magnitudes. That is to say:

(1) The results of calculations using Model 3, relative to the in situ measurements of primary production, support the theoretical results of Platt \& Sathyendranath (1991) obtained through use of a mean attenuation coefficient. 
Table 1. Water column primary production for April 1990: comparison of in situ integrated values with integrated production computed using 4 different models. In situ: observed primary production; Model 1a: primary production computed by spectral model, the equation of Sathyendranath \& Platt (1989); Model 1b: primary production computed by spectral model, the modified equation of Platt et al. (1980); Model 2: primary production computed using broad-band $\alpha$ and spectral light field; Model 3: primary production computed using broad-band $\alpha$ and $K$ calculated from under-water light field; Model 4: primary production computed by broad-band light and broad-band $\alpha$

\begin{tabular}{|c|c|c|c|c|c|c|}
\hline \multirow[t]{2}{*}{ Date } & \multicolumn{6}{|c|}{ Integrated primary production $\left(\mathrm{g} \mathrm{C}^{-2} \mathrm{~d}^{-1}\right)$} \\
\hline & In situ & Model la & Model $1 \mathrm{~b}$ & Model 2 & Model 3 & Model 4 \\
\hline April 12 & 1.71 & 2.02 & 1.71 & 1.49 & 1.98 & 0.68 \\
\hline April 13 & 1.61 & 1.66 & 1.54 & 1.23 & 1.63 & 0.54 \\
\hline April 15 & 1.63 & 1.78 & 1.63 & 1.30 & 1.83 & 0.64 \\
\hline April 16 & 1.69 & 1.70 & 1.81 & 1.45 & 2.02 & 0.54 \\
\hline April 18 & 3.24 & 3.30 & 3.04 & 2.50 & 3.51 & 1.27 \\
\hline April 19 & 2.09 & 1.92 & 1.77 & 1.46 & 2.02 & 0.79 \\
\hline April 21 & 0.87 & 0.92 & 0.84 & 0.64 & 0.89 & 0.26 \\
\hline
\end{tabular}

(2) The present results, and those of Platt \& Sathyendranath (1991), appear to offer some generality for the computations of mixed-layer production by a simplified model (Model 3). For a given biomass and mixed-layer depth, regardless of location and date, an average attenuation coefficient for the mixed layer can be estimated from the curve given by Platt \& Sathyendranath (1991, Fig. 2). This coefficient can be used to construct the submarine light field, allowing production to be computed by Model 3. If necessary, the results may be corrected through multiplication by the factor $\zeta$ to bring the results closer to those that would be calculated by the fully-spectral algorithm. The magnitude of $\zeta$ appears to vary only slightly with latitude and date. For example, the variation in $\zeta$ between December 21 at $50^{\circ} \mathrm{N}$ and March 21 at the equator for a mixed layer of $60 \mathrm{~m}$ and biomass of $1.25 \mathrm{mg} \mathrm{m}^{-3}$ is less than $5 \%$ (Figs. 3a \& 3b in Platt \& Sathyendranath 1991). The applicability of Model 3 will be limited to fairly mixed water column because of the use of $\bar{K}$ (assuming uniform biomass distribution). In stratified waters, where a typical biomass profile consists of a deep chlorophyll maximum, more complicated models that account for nonuniformity of biomass will have to be used (Platt \& Sathyendranath 1988, 1991).

Production calculated using Model 4. Primary production at depth, $P(z)$, calculated using the broad-band model, Model 4, was compared to the corresponding in situ $P(z)$. The comparison allowed us to evaluate the errors incurred by suppressing the wavelengthdependence of both $\alpha^{B}$ and $I(z)$ in estimating production. Regression slopes showed that the model's estimation of in situ $P(z)$ was poor compared to the other models. On most of the individual days, the slopes were moderately significant [with $\mathrm{p}<0.05$ for individual days $(n=9)$, and $p<0.001$ for pooled data $(n=63)]$. However, the regression slopes for the first and the last sampling days were not significant $(p>0.1, n=9)$. The values of the coefficient of determination, $\mathrm{r}^{2}$ (Fig. 11), showed that on average $60 \%$ of variance in the in situ data could be explained by regression of Model 4 results. This value is low relative to coefficients of determination for pooled data in Models 1, 2 and 3.

Water-column primary production calculated by Model 4, integrated over time and depth, was low by a

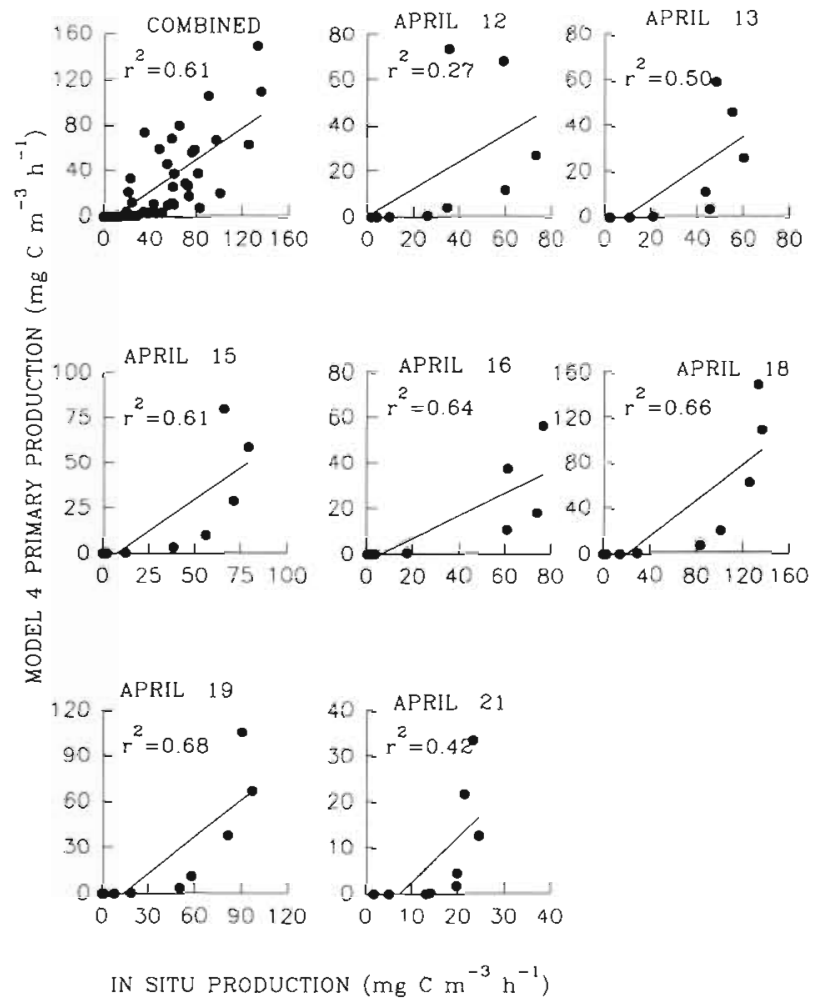

Fig. 11 As for Fig. 6, but comparison of in situ primary production, $P(z)$, with corresponding production calculated by Model 4 
factor of about 3 compared to in situ integrated primary production (Table 1). This may be attributed, in the broad-band model, to the extreme underestimation of $P(z)$, by the model, in the depth interval from 10 to $60 \mathrm{~m}$ (see Fig. 11), which the consistent overestimation at 1 and $5 \mathrm{~m}$ could not compensate. As with Model 2, which also used broad-band $\alpha^{B}$, integrated results for Model 4 were biased low compared with in situ measurements of depth-integrated primary production.

These results support the results of a similar work by Harrison et al. (1985) in which primary production was computed, up to the base of the euphotic zone $(1 \%$ light level), using the hyperbolic tangent model (Jassby \& Platt 1976). They showed that the model (non-spectral) and simulated in situ production could underestimate in situ production by 40 and $60 \%$ respectively, the results that are also consistent with earlier work of Kiefer \& Strickland (1970). However, primary production results calculated by Model 4 differ from those of the non-spectral model of Sathyendranath et al. (1989). In their theoretical calculations, the non-spectral model was found to overestimate primary production (by as much as $60 \%$ ) for higher values of chlorophyll concentration (up to $10 \mathrm{mg} \mathrm{m}^{-3}$ ) but slightly underestimate for low chlorophyll values (note however that their computation of $\bar{K}$ differs from that of Model $4: \vec{K}$ was given as the sum of attenuation coefficient due to pure seawater, $\bar{K}_{w}$; effective specific attenuation coefficient of phytoplankton, $\bar{K}_{c i}$ and attenuation due to other substances, $\bar{K}_{x}$ ). This might suggest that the extent to which broad-band models underestimate/overestimate watercolumn primary production depends, among other factors, on the concentration of chl $a$. This in turn determines the underwater light quality, as explained in Model 2 (if blue light predominates, production will be underestimated, while if green light predominates, production will be overestimated). It is also very sensitive to the method adopted for parameterizing the diffuse attenuation coefficient $\bar{K}$.

Production errors in models results relative to in situ data. Errors in daily integrated water-column primary production for the 4 tested models, relative to integrated in situ primary production, are shown for all days in Table 2. The percentage deviations in production for Models 1 and 3 showed no systematic trend, that is, for some of the days the errors were negative (overestimation of in situ production) while in others they were positive (underestimation). However, production errors shown by Models 2 and 4 were consistently positive, always underestimating in situ production.

Primary production errors for both Models $1 \mathrm{a}$ and $1 \mathrm{~b}$ were generally low, less than $9 \%$ (except for $18 \%$ on the first day with Model $1 \mathrm{a}$ and $15 \%$ for Day 6 with Model 1b). The values of integrated production, calcu-
Table 2. Percentage errors (\%) in computed primary production relative to in situ production. Model 1a: error in production computed by spectral model, the equation of Sathyendranath \& Patt (1989); Model 1b: error in production computed by spectral model, the modified equation of Platt et al. (1980); Model 2: error in production computed using broad-band $\alpha$ and spectral light field; Model 3 i error in production computed using broad-band $\alpha$ and $K$ calculated from under-water light field Model 4: error in production computed by broadband light and broad-band $\alpha$

\begin{tabular}{|c|c|c|c|c|c|}
\hline \multirow[t]{2}{*}{ Date } & \multicolumn{5}{|c|}{ Percentage error in computed production } \\
\hline & Model la & Model 1b & Model 2 & Model 3 & Model 4 \\
\hline Apr 12 & -18.4 & -0.4 & 12.6 & -16.4 & 60.0 \\
\hline Apr 13 & -3.1 & 4.2 & 24.0 & -1.1 & 66.3 \\
\hline Apr 15 & -8.8 & 0.3 & 20.2 & -11.8 & 60.7 \\
\hline Apr 16 & -0.6 & -2.6 & 14.0 & -19.5 & 69.1 \\
\hline Apr 18 & -1.9 & 5.9 & 22.8 & -8.4 & 60.8 \\
\hline Apr 19 & 8.3 & 15.3 & 29.9 & 3.4 & 62.4 \\
\hline Apr 21 & -5.1 & 3.4 & 27.0 & -1.9 & 69.8 \\
\hline
\end{tabular}

lated by Model 1, were not significantly different from the in situ integrated production $(\mathrm{p}>0.10, \mathrm{n}=7)$.

The integrated production results calculated by Model 2, when compared with in situ integrated production, showed that the model significantly $(p<0.05$, $\mathrm{n}=7$ ) underestimated in situ production from 12 to $30 \%$.

On the other hand, integrated production calculated by Model 3 was not significantly different from the in situ data $(\mathrm{p}>0.10, \mathrm{n}=7)$. The model results differed by $8.9 \%$, on average, from in situ values.

Integrated production calculated by Model 4 underestimated in situ results by more than $60 \%$ in all cases (Table 2): this difference was highly significant $(\mathrm{p}<0.001, \mathrm{n}=7)$.

\section{CONCLUSIONS}

Three conclusions can be drawn from the results of this study:

First, for the most accurate determination of daily water-column primary production, it is necessary to take into consideration the wavelength-dependence of underwater light transmission and of the photosynthesis parameter $\alpha^{B}$, as illustrated by Models $1 \mathrm{a}$ and $1 \mathrm{~b}$. Our results (Table 1, Figs. 5, $6 \&$ 7) confirm that the spectral production model, Model 1, is superior to the other models tested in estimating primary production at discrete depths and integrated through the water column. The success of Model 1 in estimating primary production lies in its ability to incorporate the angular and spectral distributions of the submarine light field in the computations of irradiance at depth, and its ability to allow, through use of the spectrally-resolved 
$\alpha^{B}(\lambda)$, for the differential efficiency with which light of different wavelengths is used in photosynthesis. In the present study, Model 1 performed well in the simplest case of homogeneous water column. For stratified waters, however, it is unlikely that the absorption spectrum and the photosynthesis parameters will be constant with depth (Platt et al. 1992). In such a case, the variation of the $P-I$ and optical parameters with depth should be taken into account.

In contrast, Model 4 is shown to be inferior to the other models in estimating water-column production. This indicates that ignoring the spectral dependence of both $\alpha^{B}$ and $I(z)$ can lead to serious errors in estimating production. Also, the results of Model 4 suggest that production estimated by the broad-band model may misrepresent the actual use of the spectral light by marine phytoplankton (Glover et al. 1985, Wood 1985 Grande et al. 1989, Laws et al. 1990).

For remotely-sensed chlorophyll, primary production at the ocean-basin scale was calculated by Platt et al. (1991). Using a spectral model (with non-uniform biomass profiles) as their benchmark, Platt et al. (1991) concluded that production computed by less complete models (broad-band, uniform biomass distribution) can differ by as much as $50 \%$ from production calculated using the spectral model. When the results of their spectral model were compared with in situ production data collected from North Atlantic Ocean during 5 different cruises (Platt \& Sathyendranath 1988) the relationship was significant. The coefficient of determination showed that at least $95 \%$ of the variance in the in situ production could be explained by the spectral model regression.

Second, Model 1 results showed that in the absence of photoinhibition, the 2 broad-band formulations, i.e. the equation of Smith (1936) and that of Platt et al. (1980), when modified to include the spectral-dependence of $\alpha^{B}$ and $I(z)$, gave equivalent estimates of water-column production. Platt et al. (1977) analyzed various broadband $P-I$ models and found that the models give satisfactory description of the observations regardless of their functional form. This, therefore, suggests that any given broad-band formulation can be modified, without bias, to compute spectral production. However, where the data show photoinhibition, one has to be careful to select a production equation that admits it.

Third, integrated production results calculated by Model 3 show that when broad-band $\alpha^{B}$ is used, watercolumn primary production can still be estimated with relatively low error if suitable calculations of underwater light transmission are performed. This conclusion was reached after comparing integrated production results of Model 3 with Model 2. Since both models used broad-band $\alpha^{B}$, but differed only in the computations of $I(z)$, water-column production esti- mated by Model 3 was better than that estimated by Model 2 because the computations of $I(z)$ in Model 3 were based on the average attenuation coefficient $\bar{K}$. Therefore, when broad-band calculations are prescribed, it is recommended that Model 3 be used whenever the necessary information exists for computation of a suitable, spectrally-averaged $\bar{K}$ for fairly homogeneous waters.

Acknowledgements. We thank Fredrick Partensky for helping with spectral data collection, Brian Irwin for providing broad-band and in situ production data, Edward Horne for light data, and Nicolas Hoepffner for helpful comments on the pathlength amplication factor. We acknowledge Osvaldo Ulloa, Glen Harrison, Bruce Johnson, Eric Mills and Jim Craigie for their constructive comments on this work. Margareth Kyewalyanga was supported by the International Center for Ocean Development (ICOD), Canada.

\section{LITERATURE CITED}

Atlas, D., Bannister, T. T. (1980). Dependence of mean spectral extinction coefficient of phytoplankton on depth, water colour, and species. Limnol. Oceanogr. 19: 1-12

Bidigare, R. R., Smith, R. C., Baker, K. S., Marra, J. (1987). Oceanic primary production estimated from measurements of spectral irradiance and pigment concentrations. Global Biogeochem. Cycles 1: 171-186

Bird, R. E. (1984), A simple, solar spectral model for directnormal and diffuse horizontal irradiance. Sol. Energy 32: $461-471$

Bricaud, A., Stramski, D. (1990). Spectral absorption coefficients of living phytoplankton and non-algal biogenous matter: a comparison between the Peru upwelling area and the Sargasso Sea. Limnol. Oceanogr. 35: 562-582

Côté, B., Platt, T. (1984). Utility of the light saturation curve as an operational model for quantifying the effects of environmental conditions on phytoplankton photosynthesis. Mar. Ecol. Prog. Ser. 18: 57-66

Eppley, R. W., Stewart, M. R., Herman, U. (1985). Estimating ocean primary production from satellite chlorophyll: introduction to regional deferences and statistics for the Southern California Bight. J. Plankton Res. 7: 57-70

Glover, H. E., Keller, M. D., Guillard, R. R. L. (1985). Light quality and oceanic ultraphytoplankters. Nature, Lond. 319: $142-143$

Grande, K. D., Leb Williams, P. J., Marra, J., Purdie, D. A., Heinemann K., Eppley, R. W., Bender, M. L. (1989). Primary production in the North Pacific gyre: a comparison of rates determined by the ${ }^{14} \mathrm{C}, \mathrm{O}_{2}$ concentration and ${ }^{18} \mathrm{O}$ methods. Deep Sea Res. 36: 1621-1634

Harrison, W. G., Platt, T, Lewis, M. R. (1985). The utility of light-saturation models for estimating marine primary productivity in the field: a comparison with conventional 'simulated' in situ methods. Can. J. Fish. Aquat. Sci. 42: $864-872$

Herman, A. W., Platt, T. (1986). Primary production profiles in the ocean: estimation from a chlorophyll/light model. Oceanol. Acta 9: 31-40

Holm-Hansen, O., Lorenzen, C. J., Strickland, J. D. H. (1965). Fluorometric determination of chlorophyll. J. Cons. int. Explor. Mer 30: 3-15 
Irwin, B., Anning, J., Caverhill, C., Hodgson, M., Macdonald, A., Platt, T. (1990). Primary production in the Northern Sargasso Sea in September 1988. Can. Data Rep. Fish. Aquat. Sci. No. 798, Dartmouth

Jassby, A. D., Platt, T. (1976). Mathematical formulation of the relationship between photosynthesis and light for phytoplankton. Limnol. Oceanogr. 21: 540-547

Kiefer, D., Strickland, J D. H. (1970). A comparative study of photosynthesis in seawater samples incubated under the two types of light attenuator. Limnol. Oceanogr 15 $408-412$

Kiefer, D. A., SooHoo, J. B. (1982). Spectral absorption by marine particles of coastal waters of Baja California. Limnol. Oceanogr. 27: 492-499

Kiefer, D. A., Chamberlain, S., Booth, C. R. (1989). Natural fluorescence of chlorophyll a: relationship to photosynthesis and chlorophyll concentration in the Western South Pacific Gyre. Limnol. Oceanogr. 34: 868-881

Kirk, J. T. O. (1983). Light and photosynthesis in aquatic ecosystem. Cambridge University Press, Cambridge

Kishino, M., Booth, C. R. Okami, N. (1984). Underwater radiant energy absorbed by phytoplankton, detritus, dissolved organic matter, and pure water. Limnol. Oceanogr. 28: $340-349$

Kishino, M., Takahashi, M., Okami, N., Ichimura, S. (1985). Estimation of the spectral absorption coefficients of phytoplankton in the sea. Bull. mar. Sci. 37: 634-642

Laws, E. A., Ditullio, G. R., Carder, K. L., Betzer, P. R., Hawes, $S$. (1990). Primary production in the deep blue sea. Deep Sea Res. 37: 715-730

Lewis, M. R., Warnock, R. E., Irwin, B., Platt, T. (1985a). Measuring photosynthetic action spectra of natural phytoplankton populations. J. Phycol. 21: 310-315

Lewis, M. R., Warnock, R. E., Platt, T. (1985b). Absorption and photosynthetic action spectra for natural phytoplankton populations: implications for production in the open ocean. Limnol. Oceanogr. 30: 794-806

Lewis, M. R., Warnock, R. E., Platt, T. (1986). Photosynthetic response of marine picoplankton at low photon flux. In Photosynthetic picoplankton. Can. Bull. Fish. Aquat. Sci. 214: $235-250$

Lewis, M. R., Ulloa, O., Platt, T. (1988). Photosynthetic action, absorption, and quantum yield spectra for a natural population of Oscillatoria in the North Atlantic. Limnol. Oceanogr. 33: 92-98

Mitchell, B. G., Kiefer, D. A. (1984). Determination of absorption and fluorescence excitation spectra for phytoplankton. In: Holm-Hansen, O., Bolis, L., Gilles, R. (eds.) Marine phytoplankton and productivity. Springer-Verlag, Berlin, p. $157-169$

Mitchell, B. G., Kiefer, D. A. (1988a). Chlorophyll a specific absorption and fluorescence excitation spectra for light limited phytoplankton. Deep Sea Res. 35: 639-663

Morel, A. (1978). Available, usable, and stored radiant energy in relation to marine photosynthesis. Deep Sea Res. 25: 673-688

Morel, A. (1980). In-water and remote measurements of ocean colour. Boundary-Layer Meteorology 18: 177-201

Morrow, J. H., Chamberlin, W. S., Kiefer, D. A. (1989). A twocomponent description of spectral absorption by marine particles. Limnol. Oceanogr. 34: 1500-1509

Pickett, J. M., Myers, J (1966). Monochromatic light saturation curves for photosynthesis in Chlorella. Plant Physiol. 41: $90-98$

Platt, T. (1986). Primary production of the ocean water column as a function of surface light intensity: algorithms for remote sensing. Deep Sea Res. 33: 149-163
Platt, T., Caverhill, C., Sathyendranath, S. (1991). Basin-scale estimates of oceanic primary production by remote sensing: the North Atlantic. J. geophys. Res. 96: 15147-15159

Platt, T., Denman, K. L., Jassby, A. D. (1977). Modeling the productivity of phytoplankton. In: Goldberg, E. D. (ed.) The sea, Vol. 6. Wiley, New York, p. 807-856

Platt, T., Gallegos, C. L., Harrison, W. G. (1980). Photoinhibition of photosynthesis in natural assemblages of marine phytoplankton. J. mar. Res. 38: 687-701

Platt, T., Herman, A. W. (1983). Remote sensing of phytoplankton in the sea: surface layer chlorophyll as an estimate of water-column chlorophyll and primary production. Int. J. Remote Sensing 4: 343-351

Platt, T., Irwin, B. (1968). Primary productivity measurements in St. Margaret's Bay. Tech. Rep. Fish. Res. Bd Can. No. 77

Platt, T., Sathyendranath, S. (1988). Ocean primary production: estimation by remote sensing at local and regional scales. Science 241: 1613-1620

Platt, T., Sathyendranath, S. (1991). Biological production models as elements of coupled, atmosphere-ocean models for climate research. J. geophys. Res. 96: 2585-2592

Platt, T., Sathyendranath, S., Caverhill, C. M., Lewis, M. R. (1988). Ocean primary production and available light: further algorithms for remote sensing. Deep Sea Res. 35: $855-879$

Platt, T., Sathyendranath, S., Ulloa, O., Harrison, W. G., Hoepffner, N., Goes, J. (1992). Nutrient control of phytoplankton photosynthesis in the Western North Atlantic. Nature, Lond. 356: 229-231

Prieur, L., Sathyendranath, S. (1981). An optical classification of coastal and oceanic waters based on the specific spectral absorption curves of phytoplankton pigments, dissolved organic matter, and other particulate materials. Limnol. Oceanogr. 26: 671-689

Richardson, K. (1991). Comparison of ${ }^{14} \mathrm{C}$ primary production determinations made by different laboratories. Mar. Ecol. Prog. Ser. 72: 189-201

Sathyendranath, S., Lazzara, L., Prieur, L. (1987). Variations in the spectral values of specific absorption of phytoplankton. Limnol. Oceanogr. 32: 403-415

Sathyendranath, S., Platt, T. (1988). The spectral irradiance field at the surface and in the interior of the ocean: a model for application in oceanography and remote sensing. J. geophys. Res. 93: 9270-9280

Sathyendranath, S., Platt, T (1989a). Computation of aquatic primary production: extended formalism to include effects of angular and spectral distribution of light. Limnol. Oceanogr. 34: 188-198

Sathyendranath, S., Platt, T. (1989b). Remote sensing of ocean chlorophyll: consequence of non-uniform pigment profile. Appl. Optics 28: 490-495

Sathyendranath, S., Platt, T., Caverhill, C. M., Warnock, R. E., Lewis, M. R. (1989). Remote sensing of oceanic primary production: computations using a spectral model. Deep Sea Res. 36: 431-453

Schofield, O., Bidigare, R. R., Prezelin, B. B. (1990). Spectral photosynthesis, quantum yield and blue-green light enhancement of productivity rates in the diatom Chaetoceros gracile and the prymnesiophyte Emiliania huxleyi. Mar. Ecol. Prog. Ser. 64: 175-186

Shibata, K. (1958). Spectrophotometry of intact biological materials. J. Biochem. 45: 599-623

Siegel, D. A., Iturriaga, R., Bidigare, R. R., Smith, R. C., Pak, H., Dickey, T. D., Marra, J., Baker, K. S. (1990). Meridional variations of the spring-time phytoplankton community in the Sargasso Sea. J. mar. Res. 48: 379-412 
Smith, E. L. (1936). Photosynthesis in relation to light and carbon dioxide. Proc natl Acad. Sci. U.S.A. 22: 504-511

Smith, R. C. (1981). Remote sensing and depth distribution of ocean chlorophyll. Mar. Ecol. Prog. Ser. 5: 359-361

Smith, R. C., Eppley, W., Baker, K. S. (1982). Correlation of primary production as measured aboard in Southern California coastal waters and as estimated from satellite chlorophyll images. Mar. Biol. 66: 1-8

Strickland, J. D. H., Parsons, T J. (1965). A manual of seawater analysis. Bull. Fish. Res. Bd Can. 125: 1-302

Strickland, J. D. H., Parsons, T. J. (1972). A practical handbook

This article was submitted to the editor of seawater analysis. Bull. Fish. Res. Bd Can. 167: 1-311

Wood, M. A. (1985). Adaptation of photosynthetic apparatus of marine ultraphytoplankton to natural light fields. Nature, Lond. 316: 253-255

Wroblewski, J. S., Sarmiento, J. L., Flierl, G. R. (1988). An ocean basin scale model of plankton dynamics in the North Atlantic. 1. Oceanographic conditions in May. Global biogeochem. Cycles 2: 199-218

Yentsch, C. S., Menzel, D. W. (1963). A method for determination of phytoplankton chlorophyll and phaeophytin by fluorescence. Deep Sea Res. 10: 221-231

Manuscript first received: March 18, 1992

Revised version accepted: June 22, 1992 